\title{
SOCIODEMOGRAFIA DOS AGRICULTORES FAMILIARES: CONTRIBUIÇÕES DA FEIRA LIVRE PARA SUSTENTAÇÃO DO SISTEMA
}

\author{
Daiane Pavan* \\ Silvio Santos Junior*
}

RESUMO: Nas últimas décadas, a agricultura familiar assumiu importância estratégica para o desenvolvimento sustentável. No Brasil, a partir da década de 1990, a classe passou a ser reconhecida e programas institucionais foram desenvolvidos. Neste contexto o município de Chapecó (SC), na tentativa de mitigar o êxodo rural o poder público, agricultores e consumidores, em 1998, criaram as feiras livres, nas quais os agricultores tiveram a oportunidade de comercializar seus produtos diretamente aos consumidores. Assim, esta pesquisa teve como objetivo geral analisar as características sociodemográficas do feirante e identificar as contribuições das feiras livre de Chapecó (SC) para o fortalecimento da agricultura familiar. A pesquisa caracteriza-se como qualitativa de caráter descritivo, sendo a coleta de dados realizada por meio de entrevista semiestruturada, com 12 famílias de agricultores feirantes, bem como a observação não participativa nas feiras livres. A interpretação dos dados ocorreu mediante a análise narrativa. Os achados revelam que as propriedades se caracterizam como minifúndios, com uma força de trabalho envelhecida e número de integrantes reduzido. Revelou também que as feiras livres representam uma alternativa para diversificação de renda e produção, acesso aos mercados e permanência na atividade rural.

PALAVRAS-CHAVE: Agricultura familiar; Sociodemografia; Feira livre; Estratégia.

\section{SOCIAL AND DEMOGRAPHIC STATUS OF FAMILIAL FARMERS: THE CONTRIBUTION OF FAIRS TO SUPPORT THE SYSTEM}

\footnotetext{
ABSTRACT: During the last decades, family agriculture turned out to have a strategic importance in sustainable development. In 1990s Brazil, this social class has been acknowledged and institutional programs have been developed in its favor. In 1998,

Mestre em Administração; pesquisadora no grupo competitividade do agronegócio, da Unoesc, com foco em agricultura familiar; Docente da Universidade do Oeste de Santa Catarina (Unoesc), Brasil; E-mail: daiane. pavan@unoesc.edu.br

** Doutor do Programa de Mestrado Profissional em Administração da Universidade do Oeste de Santa Catarina (Unoesc), Brasil.
} 
the municipal authorities of Chapecó SC Brazil, together with farmers and consumers, established agricultural fairs to mitigate rural exodus. The farmers have an opportunity to commercialize their products directly. Current qualitative and descriptive research analyzes the social and demographic features of the fair marketer and identifies the contributions of fairs in Chapecó to strengthen and improve family agriculture. Data were collected by a semi-structured interview with 12 families of fair marketers and non-participating stances in fairs. Data interpretation occurred through narrative analysis and revealed that all farms were small, with an aging working force and diminishing participating people. Agricultural fairs are actually an alternative to diversify profit and production, access to markets and permanence on the farms.

KEY WORDS: Family farming; Socio-demography; Fairs; Strategy.

\section{INTRODUÇÃO}

A agricultura familiar possui relevância significativa no processo de desenvolvimento das estruturas econômica e sociais, uma vez que por meio desta atividade rural torna-se possível dinamizar fatores que influenciam na ascensão econômica, social e cultural das localidades.

No Estado de Santa Catarina, a agricultura familiar se destaca na região Oeste, pela relevância econômica da atividade para os municípios, uma vez que a exploração dos recursos naturais para sobrevivência e geração de renda esteve presente desde os primórdios. Assim, este estudo teve como locus de pesquisa o município de Chapecó, localizado na região Oeste de Santa Catarina, com influência inicialmente indígena, seguida pela ocupação dos caboclos e pelos colonizadores, predominantemente de descendência étnica alemã, italiana e polonesa, oriundos do Rio Grande do Sul.

As consequências do desenvolvimento urbano e da migração intrarregional refletem-se no inchaço das cidades e no êxodo rural. Para mitigar estes efeitos, o poder público desenvolveu, a partir de 1990, projetos de fomento para a agricultura familiar, e, nesta carteira, constituíram-se as feiras livres onde os produtores comercializam seus produtos diretamente aos consumidores. 
As Feiras Livres de Produtos Coloniais e Agroecológicos surgiram enquanto projeto público para a agricultura familiar em 1997, com o objetivo de garantir a permanência do pequeno agricultor familiar na atividade rural (SEDEMA, 2013). Segundo a Sedema (2013), são dez pontos onde acontecem as feiras, distribuídos nos bairros da cidade, nos quais contam com 93 bancas e 60 famílias de agricultores feirantes. Nas feiras são comercializados produtos coloniais e agroecológicos, sendo que cada banca pertence a uma família que realiza a venda direta aos consumidores, propiciando uma relação de confiança e reciprocidade entre as partes.

Este estudo propõe-se a responder a questão de pesquisa relacionada a qual relevância as feiras livres tem, enquanto estratégias para o fortalecimento da agricultura familiar do município de Chapecó (SC)? Para tanto, tem-se como objetivo geral: analisar as características sociodemográficas do feirante e identificar as contribuições das feiras livre de Chapecó (SC) para o fortalecimento da agricultura familiar. Para seu êxito constituem-se os objetivos específicos da pesquisa: a) caracterizar o perfil dos agricultores participantes das feiras livre; b) compreender a relação entre as feiras livres e a diversificação de renda e produção dos agricultores familiares.

O estudo estrutura-se da seguinte maneira: inicialmente contextualização da região Oeste e a agricultura familiar; seguido da abordagem sobre diversificação da renda e da produção atividade rural; o histórico das Feiras Livres de Produtos Coloniais e Agroecológicos de Chapecó, procedimento metodológicos do estudo e a análise dos dados com a caracterização do perfil dos agricultores participantes das feiras livre e a discussão quanto à relação entre as feiras livres e a diversificação de renda e produção dos agricultores familiares.

\section{AGRICULTURA FAMILIAR E A REGIÃO OESTE DE SANTA CATARINA}

O conceito de agricultura familiar perpassa pela análise da forma de gestão das propriedades, grau de parentesco e da força de trabalho empregada para a transformação da matéria-prima e comercialização da produção.

Desse modo, com base em Mior (2005), entende-se que agricultura familiar refere-se às propriedades rurais com atividades de trabalho direto, nas quais a gestão 
esteja sob a responsabilidade das próprias famílias, que produzem para sua subsistência e comercializam seus produtos para geração de renda. Esta definição está de acordo com o cenário da agricultura familiar no Brasil que a atividade se apresenta historicamente relevante para o desenvolvimento das localidades e a geração de desenvolvimento econômico rural (MIOR, 2005).

Para Abramovay (1998, p. 146), "a agricultura familiar é aquela em que a gestão, a propriedade e a maior parte do trabalho, vêm de indivíduos que mantêm entre si laços de sangue ou de casamento", sendo combinadas as funções de administrador da produção e de trabalhador. Segundo o autor três atributos básicos estão presentes na agricultura familiar: gestão, propriedade e o trabalho familiar.

Historicamente no Brasil a agricultura familiar tem um para o Brasil, a agricultura familiar tem historicamente um papel determinante na economia, pois se apresentou como relevante para o desenvolvimento e ocupação produtiva das localidades, além de ser responsável pelo fornecimento dos alimentos para consumo da população e geração de riquezas (MIOR, 2005). Assim surgem programas específicos para a agricultura familiar, a exemplo da criação do Programa Nacional de Fortalecimento da Agricultura Familiar (Pronaf) em 1996, que consolidou a interferência governamental na atividade agrícola (SCHNEIDER, 2006).

A região Oeste de Santa Catarina tem relação direta com a atividade extrativista, seja pela exploração dos recursos naturais para sobrevivência praticada pelos indígenas pertencentes às tribos Kaigangs, Guaranis ou pela extração madeireira das florestas de araucárias pelos primeiros colonizadores (PAIM, 2006). O subsequente desenvolvimento das agroindústrias provocou profundas transformações na região, uma vez que propiciou a instalação de outras atividades comerciais. Com a modernização dos frigoríficos, implantou-se um sistema de parceiras na criação tanto de suínos quanto de aves. Esta parceria foi denominada de integração, na qual o produtor fornece a mão de obra, estrutura física da propriedade e recebe os animais na unidade de produção para criação, assistência técnica e medicamentos. Neste modelo, a agroindústria gradativamente passou a ter o controle de todo o processo, enquanto os produtores tiveram que se adequar ao sistema, num processo de mudança cultural, uma vez que os meios de produção são padronizados com objetivo de engorda do animal rapidamente e com menos insumos (PAIM, 2006). 
Durante a década de 1940 a atividade da suinocultura já transformava a região em referência na produção de carne, o que se expandiu ainda mais com as melhorias na geração de energia elétrica, assim, os frigoríficos adquiriram câmeras frigoríficas, aumentando a capacidade de atender ao mercado (KONRAD, SILVA 2012).

Nas décadas de 1960 e 1970 a região Oeste expandiu-se rapidamente, motivada pela visibilidade conquistada pela agroindústria no cenário nacional, que por sua vez, atraiu um contingente populacional elevado, com a expansão do setor educacional, dos setores comerciais e prestadores de serviço.

Nas décadas de 1980 e 1990, conforme Mior (2007, p. 6) "as mudanças tecnológicas e organizacionais introduzidas na produção suinícola começam a minar a tradicional forma de inserção da produção familiar, com maior especialização e concentração da produção." As agroindústrias passam a se inserir nas propriedades rurais da região Oeste, por meio do sistema de integração, no qual as exigências de padronização e infraestrutura para produção conforme as exigências para a exportação da carne trouxeram dificuldades de adaptação para as famílias agricultoras.

Neste contexto, a agricultura familiar desenhou-se de maneira adaptativa. Segundo Lamarche (1998, p. 239), "a atividade ocupa um espaço próprio, no qual tem a capacidade de adaptar-se aos contextos sociais e políticos no qual foi exposta historicamente", seja pela necessidade de moldar-se aos mercados, pelas exigências dos consumidores, legislações, e/ou fornecedores. Assim, a diversificação de renda e produção tornou-se vital para garantir a competitividade e a sustentabilidade da agricultura familiar, aspectos que serão detalhados na seção seguinte.

\section{A DIVERSIFICAÇÃO DA RENDA E DA PRODUÇÃO NA AGRICULTURA FAMI- LIAR}

A diversificação produtiva e de renda da agricultura familiar caracteriza-se inicialmente pela produção primária em pequenas propriedades, com vistas ao autoconsumo, tendo nos membros da família a força do trabalho da propriedade. Segundo Lamarche (1998), as propriedades tinham a necessidade de diversificar a produção, uma vez que a alimentação familiar necessitava desta variedade produtiva. 
A figura do produtor rural passa a ter notoriedade, no Brasil, a partir dos anos 1990, quando os movimentos sindicais ganham força e empreendem a luta pelo crédito, acesso aos mercados e à consolidação desta categoria produtiva, bem como ganha força a discussão dos temas relacionados à agricultura familiar no meio científico. Nessa época, a pequena atividade rural, anteriormente centrada no autoconsumo, volta-se à complementação de renda por meio de atividades agrícolas e não agrícolas, como artesanato e o comércio, o que tornou a atividade rural diversificada tanto em produção quanto em forma de geração de renda (SCHNEIDER; NIEDERLE, 2008).

O conceito de diversificação, citado por Pelinski et al. (2006), consiste em multifuncionalidade, com a realização de várias atividades desempenhadas por uma única pessoa. Para Blad (2010), a diversificação está associada ao local de trabalho, neste contexto, a gama de produtos e serviços produzidos e vendidos é ampliada, ou seja, utiliza-se dos recursos disponíveis no local de trabalho para obter valor agregado. No caso das propriedades familiares rurais este conceito é ampliado, uma vez que a propriedade tem funções residenciais, ambientais, turísticas, políticas, sociais e culturais, apresentando-se como uma unidade de trabalho múltipla, com diversas oportunidades de produção e, consequentemente, renda.

Este conceito empregado à atividade rural gera novas oportunidades de negócios, aproveitamento do espaço produtivo, otimização dos recursos e a sustentabilidade da atividade. Esta diversificação é fruto de um processo de revitalização das formas de produção no meio rural à transformação dos espaços rurais por influências sociais, econômicas e ambientais, fazendo com que o agricultor familiar busque se adaptar às novas formas de vida e produção (MARSDEN, 1990).

De acordo com Richetti (2009), as atividades desenvolvidas nas propriedades rurais podem ser classificadas em especializadas ou diversificadas. As especializadas são aquelas com base em uma única atividade, já as atividades diversificadas são aquelas onde na propriedade são produzidos diversos produtos. Nesta pesquisa, o enfoque será em ambas as classificações, uma vez que os feirantes do município de Chapecó têm a maioria da produção e comercialização voltadas ao mercado, embora exerçam outras atividades na propriedade.

A diversificação no setor rural está associada ao tempo, localidade e ambiente onde a propriedade está inserida, sendo heterogênea, pois está condicionada ao 
processo econômico, pressões e possibilidades da economia rural (ELLIS, 2007). Neste sentido as feiras livres são alternativas de diversificação que advém de um contexto de múltiplas facetas, e a seção que segue contextualiza o caso em estudo.

\section{AS FEIRAS LIVRES DE PRODUTOS COLONIAIS E AGROECOLÓGICOS DE CHAPECÓ}

As feiras livres originam-se na Idade Média, na Europa, por meio da comercialização e troca da produção do excedente produzido nos feudos, sendo responsável pelo desenvolvimento de inúmeras cidades. No renascimento comercial durante o século XIII, surgiram polos comerciais nas cidades de Veneza e Florença, sendo realizadas sem data e local fixo (NAGEL et al., 2007).

Neste modelo, a realização de feiras livres disseminou-se pela Europa e posteriormente na América Latina. No Brasil, estes espaços constituíram-se com sentido além das relações comerciais, sendo a base para formação sociocultural das localidades, e replica-se também para as feiras livres localizadas na cidade de Chapecó.

A região Oeste de Santa Catarina tem a agricultura familiar em sua concepção, determinando condições de renda, referenciais culturais e sociais para as localidades (MIOR, 2005; PAIM, 2006; KONRAD; SILVA 2012), e esta pesquisa terá como ênfase o município de Chapecó. O município destaca-se pelo crescimento acelerado nos aspectos populacionais, econômicos tendo como base o crescimento da instalação de conglomerados agroindustriais.

A partir de 1990, a indústria frigorífica passa a exigir dos produtores padrões de produção, de acordo com as demandas dos contratos internacionais para comercialização dos produtos, o que, por sua vez, gera a necessidade de investimentos e adaptação das propriedades rurais. Diante das exigências das grandes agroindústrias, as pequenas propriedades rurais, em sua maioria, já não produziam de maneira independente. Os produtores rurais organizados em grupos buscam diferenciar-se da grande agroindústria pela comercialização de "produtos coloniais", os quais são produtos processados em estabelecimentos agrícolas pelos agricultores, com finalidade de autoconsumo familiar e o excedente para comercialização (DORIGON, 2010). 
A prefeitura municipal de Chapecó realiza o custeio de despesas com a locação dos terrenos nos quais as feiras funcionam, enquanto os agricultores arcam com despesas relacionadas à energia elétrica, água e imposto predial e territorial urbano (IPTU). Outro benefício aos feirantes é a isenção fiscal de imposto sobre circulação de mercadorias e serviços (ICMS), favorecendo a redução de custos. Em contrapartida, a prefeitura fornece aos agricultores uma listagem com dois preços, sendo um o valor médio menos $20 \%$ do cobrado pelo mercado e o outro o menor entre quatro pesquisados, assim orienta-se que os feirantes mantenham seus preços entre dos dois valores, mas não existe normatização ou fiscalização quanto a esta orientação (SEDEMA, 2013).

O programa é composto por 90 bancas de venda, contemplando, em 2013, 60 famílias, observando que alguns produtores atuam em mais de uma banca em bairros diferentes. Os horários em que as feiras acontecem variam de acordo com a região, sendo estabelecidos pelos feirantes, tornando-se uma tradição para a população do bairro. À medida que a cidade se desenvolve as feiras também se propagam, um exemplo é o ponto localizado no loteamento Expoente, no bairro Seminário, na região Sul do município, inaugurado em 2012, com quatro bancas.

Para dar conta dos objetivos da pesquisa, a seção que segue descreve o método utilizado.

\section{PROCEDIMENTOS METODOLÓGICOS}

O procedimento adotado na classificação da pesquisa foi o estudo de caso, que segundo Yin (2010, p. 39) "é uma investigação empírica que investiga um fenômeno contemporâneo em profundidade e em seu contexto da vida real", assim, conforme delimitação do estudo foi realizado nas Feiras de Produtos Coloniais e Agroecológicos de Chapecó, localizada na região Oeste do Estado de Santa Catarina.

O estudo, de corte transversa ${ }^{3}$, foi executado de agosto de 2013 a agosto de 2014, e foram pesquisadas 12 famílias de agricultores familiares, contemplando todos os dez pontos de venda das feiras livres da cidade. Esses pontos eram ocupa-

3 Compreendido como os estudos que visualizam a situação de uma população em um momento preciso do tempo (ROUQUAYROL; ALMEIDA, 2006). 
dos por 60 feirantes que detinham as 93 bancas de venda de produtos coloniais e agroecológicos.

A pesquisa caracteriza-se como qualitativa e buscou obter informações por meio das particularidades dos respondentes e das suas narrativas individuais. A pesquisa quanto aos fins foi descritiva, pois buscou descrever e interpretar os dados estabelecendo relação entre as diversas informações prestadas, podendo assim analisar as contribuições das feiras livre de Chapecó (SC) para o fortalecimento da agricultura familiar.

Como técnica de análise de dados da pesquisa escolheu-se a análise narrativa que, segundo Pentland (1999), consiste na utilização das narrativas (falas) dos respondentes para construir a realidade pesquisada, por meio de etapas sistemáticas.

\section{CARACTERIZAÇÃO DOS AGRICULTORES FEIRANTES PESQUISADOS}

O estudo se deu sobre 12 famílias de feirantes. Foram entrevistados os responsáveis pelo gerenciamento da banca na feira, sendo observado que estes, em todos os casos, eram os mantenedores da família, revelando de forma subjacente a importância desta atividade para o grupo familiar.

Inicialmente, buscou-se identificar se as famílias feirantes enquadram-se na lei n. 11.326/2006 agricultor familiar, aquele que não detenha, a qualquer título, área superior a quatro módulos fiscais. Em Chapecó, o módulo fiscal é de 20 hectares. Todos os entrevistados atendem a este quesito.

Ao se estabelecer relação dos feirantes com modelo da colonização na região Oeste de Santa Catarina com características de pequenas extensões, constatou-se que, no cenário dos feirantes de Chapecó, este modelo ainda prevalece com propriedades de tamanho pequeno, o que, por um lado, beneficia a permanência e o acesso aos programas de assistência à agricultura familiar, disponíveis pelos governos municipal, estadual ou federal.

Por outro lado, entretanto essa característica de propriedades com extensões de terras menores vem se acentuando pelas divisões das áreas entre os descendentes da

4 LEI N ${ }^{\circ} 11.326$, DE 24 DE JULHO DE 2006. Estabelece as diretrizes para a formulação da Política Nacional da Agricultura Familiar e Empreendimentos Familiares Rurais. 
família, e lança um alerta sobre a sustentabilidade do sistema, no que se refere à escala mínima necessária para dar sustentação econômica do grupo. O minifúndio no Brasil é historicamente relacionado à agricultura de subsistência, e na região Oeste de Santa Catarina, conforme Konrad e Silva (2012), o processo de colonização distribuiu lotes com área entre 25 e 30 hectares, aproximadamente. Neste estudo a área média das famílias investigadas foi de 5,1 ha, com um mínimo de um e um máximo de 12 ha. Associado a esta problemática está o número de componentes do grupo familiar dos feirantes (que possivelmente irão dividir a fração de terra pertencente à família). Considerando todas as 12 famílias entrevistadas, os membros do grupo totalizaram um total de 42 pessoas, obtendo-se uma média de 3,5 membros por família.

Para melhor caracterização destas famílias questionou-se a composição da mesma quanto ao número de membros; idade; escolaridade e ocupação principal, dos mesmos. Os objetivos destes questionamentos referem-se, principalmente, à distinção da força de trabalho na propriedade em quantidade e idade, nível de profissionalização mediante a escolaridade.

Inicialmente, questionou-se a idade dos familiares que trabalham nas propriedades, conforme descrito na Tabela 1 .

Tabela 1. Membros da família e idade

\begin{tabular}{l|c}
\multicolumn{1}{c|}{ Membro familiar } & Idade média \\
\hline Patriarca & 52 \\
\hline Matriarca & 49 \\
\hline Filhos & 18 \\
\hline Outros (sogros, primos, irmãos) & 44 \\
\hline
\end{tabular}

Fonte: Dados da pesquisa (2014).

Neste aspecto observa-se que as idades médias indicam uma população predominantemente adulta, favorecendo a força de trabalho braçal na propriedade. Outro aspecto relevante refere-se à população infantil, quase inexistente na população pesquisada, correspondendo em média a 33,33\% do total dos grupos familiares, diferentemente da cultura estabelecida em décadas passadas, nas quais as famílias eram numerosas para gerar mão de obra que subsidiava a produção para o autoconsumo e o policultivo. 
Este cenário apresenta-se preocupante quanto à continuidade da atividade rural no município, uma vez que a população infantil tem um decréscimo, os jovens buscam alternativas de renda no meio urbano e a divisão das terras entre os herdeiros tornam-se fatores que contribuem para este enfraquecimento.

Conforme exposto por Gasson e Errington (1993), o interesse pela permanência na atividade rural por parte das gerações seguintes possui relação com a estrutura de incentivo disponível para que a atividade se perpetue. Assim, torna-se fundamental as ações desenvolvidas pelo poder público no fomento à atividade, no acesso ao crédito, aos mercados e a condições de trabalho e renda suficientemente satisfatórias que motivem as gerações a permanecer na atividade.

Esta constatação é corroborada pela evolução populacional rural no município, onde em 1960 representavam 79\% do total e, em 2010, passaram a 8,39\% (FUGITA, 2013). A redução populacional pode ser creditada a diversos fatores, como a migração das gerações para os centros urbanos em busca de trabalho, formação educacional e outros atrativos, a problemática da sucessão familiar rural, onde as gerações jovens não têm interesse em dar sequência às atividades no campo.

Dessa forma, a população rural em grande parte apresenta-se composta pelas gerações que receberam as propriedades como forma de herança; que estão na atividade desde crianças; possuem baixa escolaridade; limitada capacidade produtiva pela mão de obra envelhecida (FUGITA, 2013).

Visando verificar aspectos educacionais dos respondentes, questionou-se a escolaridade dos membros da família, obtendo os seguintes dados.

Tabela 2. Escolaridade dos membros da família

\begin{tabular}{l|c|c|c|c|c|c|c}
\hline Membro familiar & AN & FI & FC & MI & MC & SI & SC \\
\hline Patriarca & 1 & 3 & 5 & 0 & 1 & 0 & 1 \\
Matriarca & 2 & 4 & 4 & 0 & 1 & 0 & 1 \\
Filhos & 0 & 4 & 6 & 0 & 1 & 2 & 1 \\
Outros & 1 & 3 & 0 & 0 & 0 & 0 & 1 \\
\hline
\end{tabular}

Fonte: Dados da pesquisa (2014).

Legenda: (AN) Analfabeto; (FI) Fundamental incompleto; (FC) Fundamental completo; (MI) Médio incompleto; (MC) Médio completo; (SI) Superior incompleto; (SC) Superior completo.

Observa-se no contexto geral que a maioria possui o ensino fundamental completo, sendo este um dado que contribui para a gestão da propriedade rural 
familiar e autonomia dos agricultores, conforme destaca a família 5, "terminamos [marido e esposa] de estudar [ensino fundamental] há três anos, o que ajudou bastante a se virar principalmente quando precisa vir pra cidade." (informação verbal). Esta melhora na escolarização das famílias contribui para a percepção do mercado, pois se aliam experiência e conhecimento teórico para potencializar as vantagens de cada produto comercializado.

As informações coletadas nesta pesquisa permitem afirmar que as famílias passaram a ter menos membros e a investir na educação dos filhos visando melhorar a condição da propriedade pela qualificação da mão de obra, conforme ilustra o depoimento da família 9: "[...] incentivamos a filha a estudar engenharia de alimentos pra nos ajudar na produção de produtos do suíno, salame, queijo, pra vender mais e atender à vigilância." (informação verbal). Percebe-se que os agricultores investem na formação dos filhos objetivando o retorno à propriedade para contribuir com o conhecimento de gestão e não mais via trabalho braçal. Mas nem sempre isto acontece, observaram-se casos em que os filhos permanecem nas propriedades até concluir o curso e, após, formados procuram trabalho em empresas públicas ou privadas situadas no meio urbano.

Desse modo, observa-se que a continuidade do trabalho na atividade agrícola pode estar comprometida em um curto espaço de tempo, seja em virtude da média de idade dos membros da família que atuam nas propriedades ou pelo acesso à formação superior que proporciona oportunidades urbanas. Cabe destacar que esta alteração de perspectivas também é motivada pelos próprios agricultores via estímulo e custeio para que os filhos estudem em áreas do conhecimento diversas, assim nem sempre eles retornam à atividade rural, enfraquecendo a mão de obra familiar e, por consequência, a continuidade da atividade.

Tabela 3. Ocupação principal dos membros da família

\begin{tabular}{c|c|c|c|c|c}
\hline $\begin{array}{c}\text { Membro } \\
\text { familiar }\end{array}$ & $\begin{array}{c}\text { Agricul- } \\
\text { tor }\end{array}$ & $\begin{array}{c}\text { Carteira } \\
\text { assinada }\end{array}$ & $\begin{array}{c}\text { Aposen- } \\
\text { tado }\end{array}$ & $\begin{array}{c}\text { Não exerce } \\
\text { atividade }\end{array}$ & $\begin{array}{c}\text { Agricultor e apo- } \\
\text { sentado }\end{array}$ \\
\hline Patriarca & 10 & 0 & 0 & 0 & 1 \\
Matriarca & 11 & 0 & 1 & 0 & 0 \\
Filhos & 9 & 1 & 0 & 4 & 0 \\
Outros & 3 & 0 & 2 & 0 & 0 \\
\hline
\end{tabular}

Fonte: Dados da pesquisa (2014). 
A principal ocupação dos membros das famílias (Tabela 3) ocorre na atividade agrícola, para 33 membros (78,57\%). Do público que não exerce atividade remunerada, todos são compostos pelos filhos, os quais estão com idade escolar. $\mathrm{O}$ público aposentado caracteriza-se pelos fundadores da propriedade que permaneceram na localidade mediante o repasse da terra em forma de herança aos filhos, os quais, por sua vez, deram continuidade à atividade rural. A carteira assinada é representada por uma pessoa que, segundo a família, não teve interesse em trabalhar na atividade produtiva de panificados, optando por trabalhar no setor do comércio.

Observou-se também que a cultura familiar é patriarcal, ou seja, que os responsáveis pela família são os homens e conservavam a convicção, adquirida na infância, de seu papel de agricultor e mantenedor da família por meio do cultivo da terra. Corrobora Mello (2008) quando argumenta que os rapazes, desde crianças, tinham o conhecimento de seu papel enquanto mantenedores do sustento familiar. Cabe ressaltar que esta visão não é universal entre os jovens agricultores, sendo uma oportunidade para estudos futuros.

Quando questionados sobre o tempo em anos que as famílias desenvolvem a atividade rural, obteve-se uma média de 25,5 anos. Considerando a idade média dos membros das famílias ( 44 anos), observa-se que a maioria desenvolve esta atividade há décadas, sendo herança da família o cultivo da terra na mesma localidade há tantos anos.

Os resultados da pesquisa demonstraram que a totalidade das atividades agrícolas é desenvolvida em propriedade de área própria, geralmente, herança da família ou aquisição de outra propriedade mediante a venda de uma anterior.

Segundo Mello (2008), embora ajam interferências urbanas presentes nas comunidades, estas caracterizações fornecem indícios de um espaço social fechado e a criação de valores coletivos nas comunidades, relacionados principalmente à proteção mútua dos membros, assim, estabelecendo uma cultura própria mediante a necessidade de deslocamento para utilização de serviços relacionados à saúde, educação e à comercialização da produção, conforme presente na expressão da família 4 "Todos crescemos juntos, não adianta prejudicar o outro, pois se ele vai embora vem outro que não conhecemos e é pior. Tem que se ajudar na venda, pois o cliente que compra de mim também compra dela" (informação verbal). 
Nesse sentido, as feiras livres se constituem em um espaço fechado, uma vez que, mesmo que de maneira informal, os agricultores feirantes possuem valores pertencentes ao grupo de feirantes, sendo comportamentos estabelecidos que resistem às interferências urbanas trazidas pelas relações com outros agentes.

\section{DIVERSIFICAÇÃO DE RENDA E DA PRODUÇÃO DOS AGRICULTORES FAMI- LIARES PARTICIPANTES DAS FEIRAS LIVRES}

Nas feiras livres há preocupação quanto aos produtos a serem comercializados, ou seja, para que este não seja comercializado por diversos feirantes naquele ponto, evitando a concorrência interna. Os produtos comercializados pelas famílias nos pontos de venda podem ser visualizados na Tabela 8 , onde se observa a distribuição da oferta.

Cabe observar que os feirantes praticam o policultivo em suas propriedades, entretanto, para comercializarem nas feiras, restringem-se aos produtos acordados por ocasião de seu ingresso. Na Tabela 4 apresenta-se a relação de produtos comercializados nas feiras livres.

Tabela 4. Produtos comercializados nas feiras livres

\begin{tabular}{l|c}
\hline \multicolumn{1}{c}{ Produto } & Número de famílias que comercializam* \\
\hline Hortaliças & 3 \\
Frutas & 3 \\
Leite e seus derivados & 3 \\
Pães, bolo, biscoitos & 3 \\
Ovos & 1 \\
Carnes e derivados & 2 \\
Flores e plantas ornamentais & 1 \\
Mel & 1 \\
Milho & 2 \\
Cachaça & 1 \\
Doces de fruta & 1 \\
\hline
\end{tabular}

* Nota: a quantidade de produtos ofertados é maior que o número de famílias porque há feirantes que comercializam mais de um tipo de produto.

Fonte: dados da pesquisa (2014). 
O policultivo caracteriza-se como predominante nas pequenas propriedades rurais dos agricultores participantes das feiras livres de Chapecó, e, segundo Richetti (2009), é considerada como diversificada, sendo "aquela onde na propriedade são produzidos diversos produtos visando otimizar o uso dos recursos para produção". Existe nas propriedades a diversificação horizontal, sendo aquela baseada no cultivo de maior número de culturas, como, por exemplo, os produtores que comercializam hortaliças e frutas, e vertical, que prioriza a realização de várias etapas de produção de determinado produto, como dos derivados de suíno.

A renda média das famílias que participam da Feira Livre de Produtos Coloniais e Agroecológicos de Chapecó é de $\$$ \$ 4.460,00 por família/mês, mas deve-se considerar que $95 \%$ das famílias entrevistadas também comercializam seus produtos em outros espaços, como restaurantes, programas do governo municipal, diretamente nas residências etc.

As feiras livres representam a oportunidade de os agricultores em comercializar seus produtos diretamente aos consumidores, bem como é um canal para acesso a outro mercado e a segurança de renda para as propriedades, conforme ressalta a família 9: "[...] a nossa renda maior vem da feira, pois estamos aqui duas vezes por semana e é dinheiro certo, e pela feira conseguimos entrar no programa da merenda (PNAE)." (informação verbal). Nesse sentido, as feiras representam um elemento importante na dinâmica da agricultura familiar, já que propicia um ambiente favorável ao setor por meio da renda semanal e estimula as mudanças institucionais em razão de proporcionar acesso a outros mercados, como programas governamentais.

No que se refere à caracterização das famílias de agricultores familiares feirantes, pode-se afirmar que os participantes das feiras livres de Chapecó possuem características oriundas do processo de colonização da região Oeste de Santa Catarina, sendo baseado na propriedade pequena, própria e com renda baseada basicamente na atividade rural. Destaca-se, também, o policultivo, oriundo inicialmente da agricultura de subsistência e, posteriormente, ao processo de adaptação, em alguns casos, do abandono do sistema agroindustrial. 


\section{CONSIDERAÇÕES FINAIS}

O desenvolvimento da região Oeste de Santa Catarina possui relação direta com a agricultura familiar. Diante desta relevância, a criação de programas específicos para a agricultura familiar contribui para a manutenção da atividade e a geração de renda. Este estudo objetivou analisar as contribuições das feiras livre de Chapecó (SC) para o fortalecimento da agricultura familiar

Os resultados encontrados quanto ao perfil das famílias participantes das feiras indicam que as propriedades reservam características do modelo de colonização empregado na região Oeste de Santa Catarina, sendo predominantemente compostas por minifúndios; todas as propriedades pesquisadas são próprias e as atividades são desenvolvidas há mais de uma década.

A atividade rural apresentou-se com uma força de trabalho que está envelhecendo, com famílias compostas por poucos membros. A educação dos filhos apresenta-se como prioridade dos agricultores; muitos deles não retornam para a propriedade após concluir a formação, gerando um problema de sucessão familiar e consecução da atividade rural da família.

As feiras livres de produtos coloniais e agroecológicos de Chapecó apresentaram-se como uma alternativa de diversificação de renda e produção, sendo que as famílias conseguiram deixar o sistema agroindustrial para comercializar nas feiras, aumentando o mix de produtos e possibilidades de acesso aos mercados. Outro aspecto de destaque apresenta-se com o valor médio gerado nas feiras, sendo este superior à média da região e provedor da maioria da renda total das famílias.

Considerando os resultados do estudo, descrevem-se algumas recomendações para pesquisas futuras sobre a temática, observando aspectos, como segurança alimentar, ambiente institucional; sucessão familiar; as feiras livres como espaços de humanização e sociabilidade.

\section{REFERÊNCIAS}

ABRAMOVAY, R. Agricultura familiar e serviço público: novos desafios para a extensão rural. Cadernos de Ciência \& Tecnologia, v. 15, n. 1, p. 137-157, 1998. 
$\mathrm{BLAD}, \mathrm{M}$. Pluriactivity of farming families-old phenomenon in new times. Rural Areas and Development, v. 7, 2010.

DORIGON, C. O mercado informal dos produtos coloniais da região oeste de Santa Catarina. In: ENEC - ENCONTRO NACIONAL DE ESTUDOS DO CONSUMO, 5.; ENCONTRO LUSO-BRASILEIRO DE ESTUDOS DO CONSUMO TENDÊNCIAS E IDEOLOGIAS DO CONSUMO NO MUNDO CONTEMPORÂNEO, 2010, Rio de Janeiro. Anais... Rio de Janeiro, 2010.

ELLIS, F. Household strategies and rural livelihood diversification. Journal of Development Studies, Londres, v. 35, n. 1, p. 1-38, 2007.

FUGITA, C. Chapecó: estrutura e dinâmica de uma cidade média no oeste catarinense. Geo UERJ, ano 15, v. 1, n. 24, p. 312-338, jan./jun. 2013. Disponível em: < http://www.e-publicacoes.uerj.br/index.php/geouerj> . Acesso em: 02 dez. 2013.

GASSON, R.; ERRINGTON, A. The farm family business. Wallingford: Cab International, 1993. $290 \mathrm{p}$.

GIL, A. C. Como elaborar projetos de pesquisa. 5. ed. São Paulo: Atlas, 2010.

KONRAD, J.; SILVA, C. A. Agricultura familiar no Oeste Catarinense: da colônia à integração. In. ENCONTRO DE GEOGRAFIA AGRÁRIA, 2012, Uberlândia. Anais eletrônicos... 2012. Disponível em: < $w$ ww.lagea.ig.ufu.br/xx1enga/anais_enga_2012/ eixos/1153_1.pdf >. Acesso em: 12 jan. 2014.

LAMARCHE, H. et al. A agricultura familiar: comparação internacional do mito à realidade. Tradução Frédéric Bazin: Campinas: Unicamp, 1998.

MARSDEN, T. et al. Rural Reestructuring: global processos and their responses. London: David Fulton Publishers, 1990.

MELLO, M. A. Transformações sociais recentes no espaço rural do Oeste de Santa Catarina: Migração, sucessão e celibato. In: CONGRESSO DA SOCIEDADE BRASILEIRA DE ECONOMIA, ADMINISTRAÇÃO E SOCIOLOGIA RURAL - SOBER, 2008, 
Fortaleza, Ceara. Anais eletrônicos... 2008. Disponível em: <www.sober.org.br/ palestra/5/1036.pdf > . Acesso em: 12 fev. 2014.

MIOR, L. C. Agricultores familiares, agroindústrias e redes de desenvolvimento rural. Chapecó: Argos, 338 p., 2005.

MIOR, L. C. et al. Redes e agroindústrias: as inovações organizacionais dos agricultores familiares e os novos mercados em Santa Catarina. In: CONGRESSO DA SOCIEDADE BRASILEIRA DE ECONOMIA, ADMINISTRAÇÃO E SOCIOLOGIA RURAL - SOBER, 51., 2013, Belém. Anais... Belém, 2013.

NAGEL, B.; et al. Os bastidores de uma feira livre. PUC-Rio, 2007. Disponível em: < http://puc-riodigital.com.puc-rio.br/media/13\%20-\%20os\%20bastidores\%20 de\%20uma\%20feira\%20livre.pdf> . Acesso em: 17 dez. 2014.

PAIM, E. A. Aspectos da constituição histórica da região Oeste de Santa Catarina. 14. ed. João Pessoa, 2006. Disponível em: < http://www.biblionline.ufpb.br/ojs/ index.php/srh/article/viewFile/11346/6460> . Acesso em: 09 jan. 2014.

PELINSKI, A. et al. A diversificação no incremento da renda da propriedade familiar agroecológica. In: CONGRESSO BRASILEIRO DE AGROECOLOGIA, Belo Horizonte. Anais... Belo Horizonte, 2006.

PENTLAND, B. T. Building process theory from narrative: from description to explanation. Academy of management review, v. 24, n. 4, 1999.

PREFEITURA DE CHAPECÓ (Município). Chapecó: Secretaria de Desenvolvimento Rural e Meio Ambiente de Chapecó - Sedema, 2013. Disponível em: <www. chapeco.sc.gov.br>. Acesso em: $02 \mathrm{dez} .2013$.

RICHETTI, A. O que é diversificação agropecuária? Informe Agropecuário. Sindicato Rural de Campo Grande. MS. Ano XX, n. 279, setembro, 2009. Disponível em: < http://www.srcg.com.br/public/informe/1576-site-informes-agropecuarios1302280097-pdf.pdf> . Acesso em: 03 fev. 2014. 
ROUQUAYROL, M.Z, ALMEIDA FILHO, N. Epidemiologia e saúde. 6. Edição. Rio de Janeiro: Guanabara Koogan, 2006.

SCHNEIDER, S. Agricultura familiar e desenvolvimento rural endógeno: elementos teóricos e um estudo de caso. In: FROEHLICH, J. M.; DIESEL, V. (Org.). Desenvolvimento Rural: tendências e debates contemporâneos. Ijuí: Ed. Unijuí, 2006.

SCHNEIDER, S.; NIEDERLE, P. A. Agricultura familiar e teoria social: a diversidade das formas familiares na agricultura. In: FALEIRO, F. G.; FARIAS NETO, A. L. (Ed.). Savanas: desafios e estratégias para o equilíbrio entre sociedade, agronegócio e recursos naturais. Planaltina, D. F., Embrapa Cerrados, 2008, p. 989-1014.

YIN, R. K. Estudo de caso: planejamento e métodos. Porto Alegre: 4. ed. Bookmann, 2010.

Recebido em: 28 de agosto de 2015 Aceito em: 18 de outubro de 2016 